University of Rhode Island

DigitalCommons@URI

\title{
Applying MCDA to weight indicators of seaport vulnerability to climate and extreme weather impacts for U.S. North Atlantic ports
}

\author{
R. Duncan Mclntosh \\ University of Rhode Island \\ Austin Becker \\ University of Rhode Island, abecker@uri.edu
}

Follow this and additional works at: https://digitalcommons.uri.edu/maf_facpubs

\section{The University of Rhode Island Faculty have made this article openly available.}

Please let us know how Open Access to this research benefits you.

This is a pre-publication author manuscript of the final, published article.

Terms of Use

This article is made available under the terms and conditions applicable towards Open Access

Policy Articles, as set forth in our Terms of Use.

\section{Citation/Publisher Attribution}

McIntosh, R.D., Becker, A. Applying MCDA to weight indicators of seaport vulnerability to climate and extreme weather impacts for U.S. North Atlantic ports. Environ Syst Decis (2020). https://doi.org/ 10.1007/s10669-020-09767-y Available at: https://doi.org/10.1007/s10669-020-09767-y 
See discussions, stats, and author profiles for this publication at: https://www.researchgate.net/publication/340084122

Applying MCDA to weight indicators of seaport vulnerability to climate and extreme weather impacts for U.S. North Atlantic ports

Article in Environment Systems and Decisions · March 2020

DOI: $10.1007 /$ s10669-020-09767-y

CITATIONS

0

2 authors, including:

R. Duncan McIntosh

Secretariat of the Pacific Regional Environment Programme

8 PUBLICATIONS 10 CITATIONS

SEE PROFILE
READS

11 
McIntosh, R.D., Becker, A. (2020), “Applying MCDA to Weight Indicators of Seaport Vulnerability to Climate and Extreme Weather Impacts for U.S. North Atlantic Ports." Environment Systems and Decisions. Volume 40. Issue 1. 21 March 2020. doi:10.1007/s10669-020-09767-y

\title{
Applying MCDA to Weight Indicators of Seaport Vulnerability to Climate and Extreme
}

\author{
Weather Impacts for U.S. North Atlantic Ports
}

\author{
R. Duncan McIntosh ${ }^{1,2}$ and Austin Becker ${ }^{1}$ \\ ${ }^{1}$ University of Rhode Island Department of Marine Affairs' Kingston, RI 02881, mcintosh@uri.edu, \\ abecker@uri.edu \\ ${ }^{2}$ Secretariat of the Pacific Regional Environment Programme, Apia, Samoa
}

\section{Abstract}

This paper describes a case study applying multi criteria decision analysis (MCDA) to weight indicators for assessing the exposure and sensitivity of seaports to climate and extreme weather impacts. Researchers employed the Analytic Hierarchy Method (AHP) of MCDA to generate weights for a subset of expert-selected indicators of seaport exposure and sensitivity to climate and extreme weather. The indicators were selected from the results of a survey of port-experts who ranked candidate indicators by magnitude of perceived correlation with the three components of vulnerability; exposure, sensitivity, and adaptive capacity. As those port-expert respondents found significantly stronger correlation between candidate indicators and the exposure and sensitivity of a port than with a port's adaptive capacity, this AHP exercise did not include indicators of adaptive capacity. The weighted indicators were aggregated to generate composite indices of seaport exposure and sensitivity to climate and extreme weather for 22 major ports in the North East United States. Rank order generated by AHP-weighted aggregation was compared to a subjective expert-ranking of ports by expert-perceived vulnerability to climate and extreme weather. For the sample of 22 ports, the AHP-generated ranking matched three of the top four most vulnerable ports as assessed subjectively by port-experts. These results suggest that a composite index based on open-data weighted via MCDA may eventually prove useful as a data-driven tool for identifying outliers in terms of relative seaport vulnerabilities, however, improvements in the standardized reporting and sharing of port data will be required before such an indicator-based assessment method can prove decision-relevant.

Key Words: indicator, seaport, climate vulnerability, Analytical Hierarchy

Method, composite index, expert elicitation 
McIntosh, R.D., Becker, A. (2020), “Applying MCDA to Weight Indicators of Seaport Vulnerability to Climate and Extreme Weather Impacts for U.S. North Atlantic Ports." Environment Systems and Decisions. Volume 40. Issue 1. 21 March 2020. doi:10.1007/s10669-020-09767-y

\section{Introduction} \\ Seaport Vulnerability to Climate and Extreme Weather}

Seaports sit on the frontlines of our shores, consigned to battle the elements at the

hazardous intersection of land and sea. Ports face projected increases in the frequency and severity of impacts driven by changes in water-related parameters like mean sea level, wave height, salinity and acidity, tidal regime, and sedimentation rates, and port functions are expected to be increasingly affected directly by changes in temperature, precipitation, wind, and storm frequency and intensity (Koppe et al. 2012; Becker et al. 2013). At the same time, ports are often located in environmentally sensitive ecosystems such as estuaries and river mouths, which provide important nursery habitat for juvenile marine organisms (Beck et al. 2001).

As infrastructure assets, ports are critical to both the public and the private good, playing a key role in the network of both intranational and international supply-chains. Ports serve as catalysts of economic growth locally and regionally, as they create jobs and promote the expansion of nearby industries and cities (Asariotis et al. 2017).

Port decision-makers have a responsibility to manage a multitude of risks and enhance port resilience to achieve the minimum downtime safely possible in any given circumstance. When regional systems of ports are considered, responsible decision-makers may wish to prioritize limited resources, or to identify outliers among a set of ports in terms of vulnerability to certain hazards. At the single-port scale, port decision-makers (e.g., a local port authority) may question which specific adaptation actions to take, or how to start with

60 climate-adaptation. At the multi-port scale, port decision-makers (e.g., the U.S. Army Corps 61 of Engineers) may question which ports in a certain regional jurisdiction are the most vulnerable and hence the most in need of urgent attention. As climate adaptation decisions 
McIntosh, R.D., Becker, A. (2020), “Applying MCDA to Weight Indicators of Seaport Vulnerability to Climate and Extreme Weather Impacts for U.S. North Atlantic Ports." Environment Systems and Decisions. Volume 40. Issue 1. 21 March 2020. doi:10.1007/s10669-020-09767-y

63 often involve conflicting priorities (e.g., politics, national priorities, local priorities),

64 providing a data-driven, standard metric can help bring objectivity into the process.

Port decision-makers faced with climate impact, adaptation and vulnerability (CIAV)

${ }^{1}$ decisions involving multiple ports can benefit from information products that allow them to compare the mechanisms and drivers of vulnerability among ports. The indicator-based assessment described in this paper provides an example of such a product that can quantify complex issues and bring a standardized data-driven approach to measuring theoretical concepts, with the caveat that the decision-relevance of their results hinges on the quality of data available to serve as indicators.

\section{Indicator-Based Composite Indices}

Indicators are measurable, observable quantities that serve as proxies for an aspect of a system that cannot itself be directly or adequately measured (Gallopin 1997; Hinkel 2011). Indicator-based assessment methods are generally applied to assess or 'measure' features of a system that are described by theoretical concepts. Directly immeasurable, concepts such as resilience and vulnerability are instead made operational by mapping them to functions of observable metrics called indicators (McIntosh and Becker 2017). Indicator-based composite indices are multidimensional tools that synthesize multiple indicators into a single composite indicator that can represent a relative value of a theoretical concept (Dedeke 2013; McIntosh and Becker 2017). Examples of indicator-based composite indices include the Social

83 Vulnerability Index (SoVI) (Cutter et al. 2003; Cutter et al. 2010), the Earthquake Disaster 84 Risk Index (EDRI) (Davidson and Shah 1997), and the Disaster Risk Index (Peduzzi et al. 2009). Indicator-based composite indices are meant to yield a high-level overview of the

\footnotetext{
${ }^{1}$ CIAV decisions are choices, the results of which are expected to affect or be affected by the interactions of the changing climate with ecological, economic, and social systems.
} 
McIntosh, R.D., Becker, A. (2020), “Applying MCDA to Weight Indicators of Seaport Vulnerability to Climate and Extreme Weather Impacts for U.S. North Atlantic Ports." Environment Systems and Decisions. Volume 40. Issue 1. 21 March 2020. doi:10.1007/s10669-020-09767-y

relative values of a concept of interest, e.g., vulnerability, and as such, are more suited to high-level identification of relative outliers than to in-depth analyses of the concept of interest.

The SoVI, for example, compiles 29 input variables from the U.S. Census for over 66,000 census tracts to construct an index (Cutter et al. 2003). The large number of variables is reduced using Principal Component Analysis (PCA), and the resulting 6-8 principal components are named according to the highest loading factors for each component. The SoVI produces a score by summing the indicators into components and the components into the total score. The SoVI weights each indicator and component equally as the researchers lacked a theoretical basis for determining weights. For the research described in this paper, the SoVI recipe was considered, but deemed to be unsuitable for ports as the small sample size and the sparseness of available data (compared to Census data) led to difficulty in identifying and naming the principal components. Instead of the purely theoretical approach described by the SoVI, this work takes a stakeholder-driven approach by including portexperts in the development and weighting of the indicators, as this has been shown to increase the creditability of the index as a tool (Barnett et al. 2008; Sagar and Najam 1998). With a small sample size and sparse data available to construct an index of seaport vulnerability, researchers sought to create a tool that would allow subject-matter experts to input their knowledge by determining the relative importance (weight) of the different indicators making up the index. Including stakeholders in the design-stage of decisionsupport tool development can increase the stakeholders' perceptions of the credibility, salience, and legitimacy of the tool (White et al. 2010).

Indicator-based assessments and indices have provoked debate in the literature, and some researchers (Barnett et al. 2008; Eriksen and Kelly 2007; Hinkel 2011; Klein 2009; Gudmundsson 2003) have criticized attempts to assess theoretical concepts with them as 
McIntosh, R.D., Becker, A. (2020), “Applying MCDA to Weight Indicators of Seaport Vulnerability to Climate and Extreme Weather Impacts for U.S. North Atlantic Ports." Environment Systems and Decisions. Volume 40. Issue 1. 21 March 2020. doi:10.1007/s10669-020-09767-y

111 lacking scientific rigor or lacking consistency. Nonetheless, policymakers are increasingly

112 calling for the development of methods to measure relative risk, vulnerability, and resilience

113 (Cutter et al. 2010; Hinkel 2011; Rosati 2015), and developing better indicators and expert-

114 driven weighting schemes through participatory processes like AHP may lead to

115 improvements in this field. Despite these criticisms of indicator-based vulnerability

116 assessments (IBVA) and indicator-based composite indices in particular, such decision-

117 support tools can play an important role in bringing objective data into the complex decision-

118 making process. The use of such indicator-based decision-support products can provide

119 guidance in identifying areas of concern, but they should always be supplemented with

120 additional expertise as they lack the high-resolution found in more detailed case-study

121 assessment approaches.

Whereas low-level, high-resolution analyses are better served by more comprehensive case-study approaches, e.g., (Hallegatte et al. 2011; McLaughlin et al. 2011; USDOT 2014), indicator-based composite indices are well suited to provide high-level overviews of relative outliers among a sample. Indicator-based assessments and indices, then, are simply one tool among a suite of tools that decision-makers should have at their disposal.

\section{Selection of Indicators}

Researchers worked with port-experts to develop from open-sources and evaluate a

130 set of high-level indicators of seaport vulnerability ${ }^{2}$ to climate and extreme weather impacts

131 for the 22 medium and high use ports ${ }^{3}$ of the United States Army Corps of Engineers'

\footnotetext{
2 The degree to which a system is susceptible to, and unable to cope with, adverse effects of climate change, including climate variability and extremes. Vulnerability is a function of the character, magnitude, and rate of climate change and variation to which a system is exposed, its sensitivity, and its adaptive capacity. (IPCC 2001)

${ }^{3}$ Medium use here refers to ports with annual throughput $>1 \mathrm{M}$ tons and high use refers to ports with annual throughput $>10 \mathrm{M}$ tons
} 


\section{North Atlantic Medium and High Use Ports}

\section{Searsport, ME}

\section{Portland, ME •}

ePortsmouth, $\mathrm{NH}$

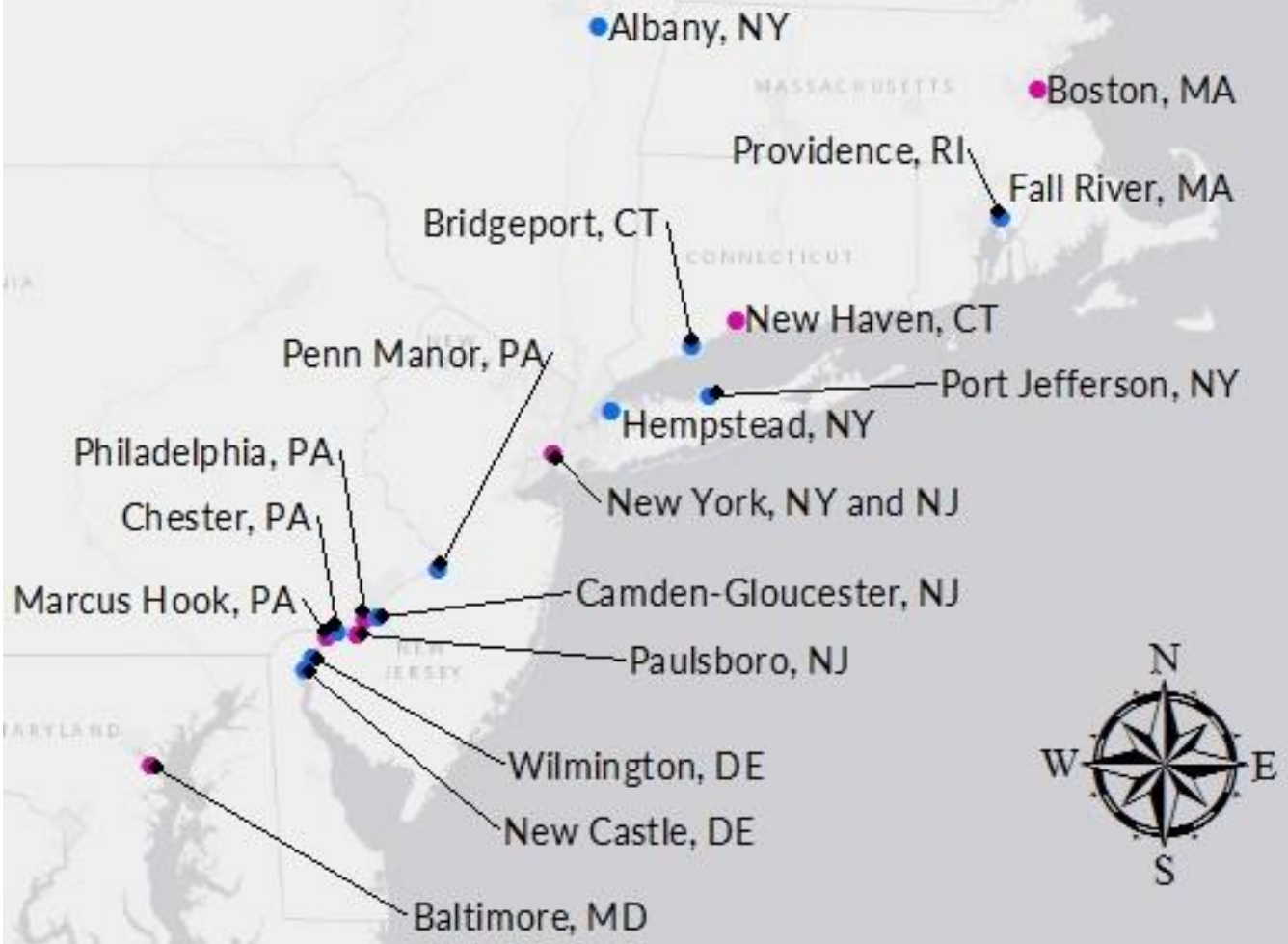

- Medium Use: $1 \mathrm{M}-10 \mathrm{M}$ Tons Annual Throughput

- High Use: >10M Tons Annual Throughput

-Hopewell, VA

Data: USACE Principal Ports 2015

-Virginia, VA, Port of

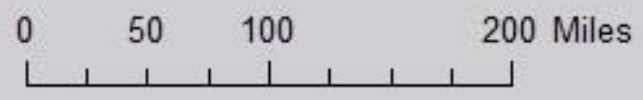

(USACE) North Atlantic Division ${ }^{4}$ (CENAD) (Figure 1).

\section{Figure 1 Study area ports}

\footnotetext{
${ }^{4}$ The North Atlantic Division is one of nine USACE divisions and encompasses the U.S. Eastern Seaboard from Virginia to Maine (USACE 2014).
} 
McIntosh, R.D., Becker, A. (2020), “Applying MCDA to Weight Indicators of Seaport Vulnerability to Climate and Extreme Weather Impacts for U.S. North Atlantic Ports." Environment Systems and Decisions. Volume 40. Issue 1. 21 March 2020. doi:10.1007/s10669-020-09767-y

134 The steps involved in compiling and evaluating this set of candidate indicators are illustrated

135 in Figure 2.

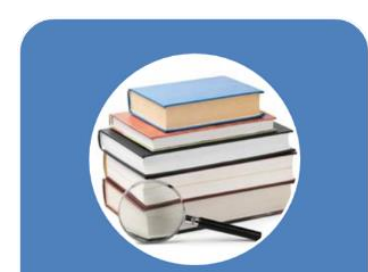

Literature Review

- Sought indicators of

exposure, sensitivity,

adaptive capacity

- 108 Candidate Indicators
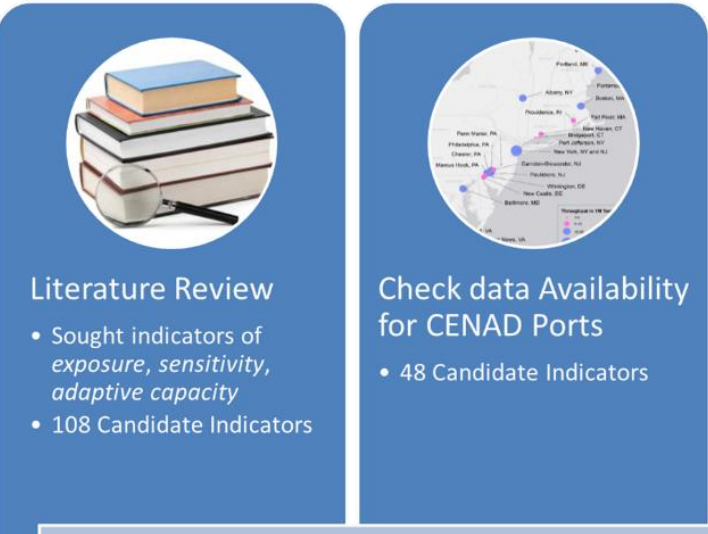

Check data Availability for CENAD Ports

- 48 Candidate Indicators

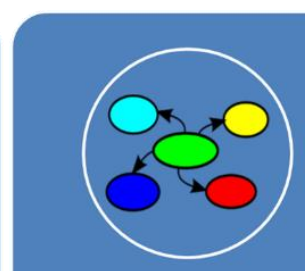

Mind Map Exercise

- CMTS RIAT evaluated

indicators for correlation

- 34 Candidate Indicators

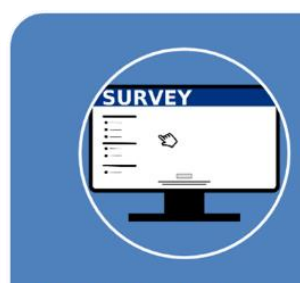

Expert Evaluation Survey

- Experts rated indicators for correlation with exposure, sensitivity and adaptive capacity

\section{Figure 2 Steps involved in compiling and evaluating candidate indicators. The AHP described in this paper uses the highest scoring indicators from the last step (survey) portrayed in this figure}

Researchers began by identifying indicators of vulnerability that were suitable for use in the AHP study (McIntosh and Becker 2019; McIntosh et al. 2019). A review of climate change vulnerability assessment (CCVA) and seaport-studies literature identified 108 candidate indicators of vulnerability. Of the 108 candidate indicators identified, 48 were found to have sufficient data for the sample of CENAD ports (Figure 1). These 48 indicators were then further distilled to 34 viable candidate indicators via a mind mapping exercise with members of the Resilience Integrated Action Team ${ }^{5}$ (RIAT) of the United States Committee on the Marine Transportation System ${ }^{6}$ (US CMTS). The 34 candidate indicators chosen via this mind map exercise were then evaluated via a visual analogue scale $^{7}$ (VAS) survey instrument by 64 port experts. For each candidate indicator in the VAS survey, respondents

\footnotetext{
${ }^{5}$ The MTS Resilience IAT (R-IAT) was established to focus on cross-Federal agency knowledge co-production and governance to incorporate the concepts of resilience into the operation and management of the U.S. Marine Transportation System.

${ }^{6}$ The United States' CMTS is a Federal Cabinet-level, inter-departmental committee chaired by the Secretary of Transportation. The purpose of the CMTS is to create a partnership of Federal departments and agencies with responsibility for the Marine Transportation System (MTS).

${ }^{7}$ In visual analogue scale (VAS), respondents measure their level of agreement by indicating a position along a continuous line segment
} 
McIntosh, R.D., Becker, A. (2020), “Applying MCDA to Weight Indicators of Seaport Vulnerability to Climate and Extreme Weather Impacts for U.S. North Atlantic Ports." Environment Systems and Decisions. Volume 40. Issue 1. 21 March 2020. doi:10.1007/s10669-020-09767-y

149 were given the indicator's description, units, data source, and example values, and

150 respondents were asked to determine whether the candidate indicator could be correlated with

151 the exposure ${ }^{8}$, sensitivity ${ }^{9}$, and/or the adaptive capacity ${ }^{10}$ of ports in the study area.

152 Respondents indicated the magnitude and direction of correlation by dragging a slider along a

153 VAS line segment (Figure 3). In addition to evaluating 34 indicators of seaport vulnerability,

154 respondents of the VAS survey also subjectively ranked the CENAD ports by magnitude of

155 perceived vulnerability to climate and extreme weather impacts.

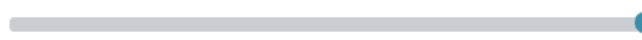

Figure 3 VAS slider for indicating expert-perceived correlation between a candidate indicator and each of the components of 158 vulnerability.

159 For the 34 candidate indicators that were evaluated, none scored a median rating

160 higher than 23 on the unitless VAS scale of correlation with adaptive capacity, compared to a

161 high of 62 with exposure and 52 with sensitivity. This low level of perceived correlation with

162 adaptive capacity suggests a dearth of open-data ${ }^{11}$ sources suitable for representing the

163 adaptive capacity of seaports to climate and extreme weather impacts. It also suggests that the

164 concept of adaptive capacity is considered by port-experts to be more difficult to represent

165 with quantitative data than the concepts of exposure or sensitivity. For these reasons, this

166 AHP exercise did not include indicators of adaptive capacity but focused instead on

167 generating weights for indicators of exposure and sensitivity.

\footnotetext{
${ }^{8}$ The presence of people, livelihoods, species or ecosystems, environmental functions, services, and resources, infrastructure, or economic, social, or cultural assets in places and settings that could be adversely affected (IPCC 2014)

${ }^{9}$ The degree to which a system is affected, either adversely or beneficially, by climate-related stimuli (IPCC 2001)

${ }^{10}$ The ability of systems, institutions, humans and other organisms to adjust to potential damage, to take advantage of opportunities, or to respond to consequences (IPCC 2014)

${ }^{11}$ Open-data refers to publicly available data structured in a way that enables the data to be fully discoverable and usable by end users without having to pay fees or be unfairly restricted in its use.
} 
McIntosh, R.D., Becker, A. (2020), “Applying MCDA to Weight Indicators of Seaport Vulnerability to Climate and Extreme Weather Impacts for U.S. North Atlantic Ports." Environment Systems and Decisions. Volume 40. Issue 1. 21 March 2020. doi:10.1007/s10669-020-09767-y

As AHP best-practice recommends each category should have at least 4, but not more

169 than 7 to 10 sub-categories (Goepel 2013), researchers selected the 6 highest scoring

170 indicators for exposure and the 6 highest scoring indicators for sensitivity for inclusion in the

171 AHP exercise (Table 1) described in the following section.

172 Table 1The six indicators rated highest for correlation with seaport exposure and sensitivity to climate and extreme weather 173 impacts.

\begin{tabular}{|c|c|c|c|c|}
\hline Category & Description & Indicator & Units & Data Source \\
\hline \multirow[t]{6}{*}{ Exposure } & $\begin{array}{l}\text { Number of storm events in port } \\
\text { county w/ property damage }>\$ 1 \mathrm{M}\end{array}$ & $\begin{array}{l}\text { NumberStormEvent } \\
\text { s }\end{array}$ & events & $\begin{array}{l}\text { NOAA Storm } \\
\text { Events Database }\end{array}$ \\
\hline & $\begin{array}{l}1 \% \text { annual exceedance probability } \\
\text { high water level which corresponds } \\
\text { to the level that would be exceeded } \\
\text { one time per century, for the nearest } \\
\text { NOAA tide station to the port }\end{array}$ & $\begin{array}{l}\text { HundredYearHigh } \\
\text { Water }\end{array}$ & $\begin{array}{l}\mathrm{m} \text { above } \\
\text { MHHW }\end{array}$ & $\begin{array}{l}\text { NOAA Tides } \\
\text { and Currents: } \\
\text { Extreme Water } \\
\text { Levels }\end{array}$ \\
\hline & $\begin{array}{l}\text { Number of cyclones that have } \\
\text { passed within } 100 \mathrm{~nm} \text { of the port } \\
\text { since } 1842\end{array}$ & NumberCyclones & $\begin{array}{l}\text { Number of } \\
\text { cyclones }\end{array}$ & $\begin{array}{l}\text { NOAA } \\
\text { Historical } \\
\text { Hurricane } \\
\text { Tracks Tool } \\
\end{array}$ \\
\hline & Local Mean Sea Level Trend & SeaLevelTrend & $\mathrm{mm} / \mathrm{yr}$ & $\begin{array}{l}\text { NOAA Tides } \\
\text { and Currents }\end{array}$ \\
\hline & $\begin{array}{l}\text { The percent change from observed } \\
\text { baseline of the average number of } \\
\text { "Extremely Heavy" Precipitation } \\
\text { Events projected for the end-of- } \\
\text { century, downscaled to } 12 \mathrm{~km} \\
\text { resolution for the port location }\end{array}$ & $\begin{array}{l}\text { CMIP_NumberOfE } \\
\text { xtremelyHeavyPreci } \\
\text { pEvents }\end{array}$ & $\%$ & $\begin{array}{l}\text { US DOT CMIP } \\
\text { Climate Data } \\
\text { Processing Tool }\end{array}$ \\
\hline & $\begin{array}{l}\text { Number of Presidential Disaster } \\
\text { Declarations for the port county } \\
\text { since } 1953\end{array}$ & $\begin{array}{l}\text { NumberDisastersCo } \\
\text { unty }\end{array}$ & $\begin{array}{l}\text { Disaster } \\
\text { Type }\end{array}$ & $\begin{array}{l}\text { FEMA, } \\
\text { Historical } \\
\text { Declarations }\end{array}$ \\
\hline \multirow[t]{6}{*}{ Sensitivity } & $\begin{array}{l}\text { Number of Critical Habitat Areas } \\
\text { within } 50 \text { miles of the port }\end{array}$ & $\begin{array}{l}\text { NumberCriticalHab } \\
\text { itat }\end{array}$ & Areas & $\begin{array}{l}\text { U.S. Fish \& } \\
\text { Wildlife Service }\end{array}$ \\
\hline & $\begin{array}{l}\text { Environmental Sensitivity Index } \\
\text { (ESI) shoreline sensitivity to an oil } \\
\text { spill for the most sensitive shoreline } \\
\text { within the port }\end{array}$ & ESI & ESI Rank & $\begin{array}{l}\text { NOAA Office of } \\
\text { Response and } \\
\text { Restoration }\end{array}$ \\
\hline & $\begin{array}{l}\text { Average cost of property damage } \\
\text { from storm events in the port county } \\
\text { since } 1950 \text { with property damage }> \\
\$ 1 \text { Million }\end{array}$ & $\begin{array}{l}\text { AvgCostStormEven } \\
\text { ts }\end{array}$ & \$USD & $\begin{array}{l}\text { NOAA Storm } \\
\text { Events Database }\end{array}$ \\
\hline & $\begin{array}{l}\text { Rate of population change (from } \\
2000-2010 \text { ) in the port county, } \\
\text { expressed as a percent change }\end{array}$ & $\begin{array}{l}\text { PopulationChangeC } \\
\text { ounty }\end{array}$ & $\%$ & $\begin{array}{l}\text { NOAA Office } \\
\text { for Coastal } \\
\text { Management }\end{array}$ \\
\hline & $\begin{array}{l}\text { Percent of the port county } \\
\text { population living inside the FEMA } \\
\text { Floodplain }\end{array}$ & $\begin{array}{l}\text { PopulationInsideFlo } \\
\text { odplain }\end{array}$ & $\%$ & $\begin{array}{l}\text { NOAA Office } \\
\text { for Coastal } \\
\text { Management } \\
\end{array}$ \\
\hline & $\begin{array}{l}\text { Port County Social Vulnerability } \\
\text { (SoVI) Score }\end{array}$ & SoVI & $\begin{array}{l}\text { score } \\
\text { number }\end{array}$ & $\begin{array}{l}\text { SoVI® Social } \\
\text { Vulnerability } \\
\text { Index }\end{array}$ \\
\hline
\end{tabular}

175 Analytic Hierarchy Process

177 in the field of decision science that allows a structural approach to enable analysis of different 
McIntosh, R.D., Becker, A. (2020), “Applying MCDA to Weight Indicators of Seaport Vulnerability to Climate and Extreme Weather Impacts for U.S. North Atlantic Ports." Environment Systems and Decisions. Volume 40. Issue 1. 21 March 2020. doi:10.1007/s10669-020-09767-y

178 alternatives, information, and judgements (Linkov and Moberg 2011; Kurth et al. 2017;

179 Cegan et al. 2017). Benefits of MCDA include the ability to provide a formal platform for

180 stakeholder engagement (Linkov and Moberg 2011; Kurth et al. 2017; Cegan et al. 2017).The

181 Analytic Hierarchy Process (AHP) is a method of MCDA first described by Thomas Saaty

182 (Saaty 1977) that is based on the solution of an eigenvalue problem. Participants make

183 pairwise comparisons, the results of which are arranged in a matrix where the dominant

184 normalized right eigenvector gives the ratio scale (weighting) and the eigenvalue determines

185 the consistency ratio (Goepel 2013; Saaty 1977, 1990b, 2006). AHP has become well

186 established for group decisions based on the aggregation of individual judgements

187 (Ramanathan and Ganesh 1994; Dedeke 2013; Goepel 2013). Psychologists have noted that

188 respondents have an easier time making judgements on a pair of alternatives at a time than

189 simultaneously on all the alternatives (Ishizaka and Labib 2011). AHP also allows

190 consistency cross checking between the pairwise comparisons. Additionally, AHP uses a

191 ratio scale, which, unlike methods using interval scales, does not require units in the

192 comparison (Kainulainen et al. 2009; Hovanov et al. 2008). Compared to other MCDA

193 methods, such as multi-attribute utility theory (MAUT) or multi-attribute value theory

194 (MAVT), the assumption of a rational decision maker is much less stringent in AHP due to

195 AHP's ability to incorporate consistency ratios (Linkov and Ramadan 2004; Linkov and

196 Moberg 2011).

AHP has also proven useful as a standardized method for generating the weights of

198 indicators in composite indices in a variety of different fields, e.g., environmental

199 performance index (EPI) (Dedeke 2013), disaster-resilience index (Orencio and Fujii 2013),

200 composite indicator of agricultural sustainability (Gómez-Limón and Riesgo 2009), and the

201 urban public transport system quality (Pticina and Yatskiv 2015). While these studies assessed different theoretical concepts from performance, to disaster-resilience, to 
McIntosh, R.D., Becker, A. (2020), “Applying MCDA to Weight Indicators of Seaport Vulnerability to Climate and Extreme Weather Impacts for U.S. North Atlantic Ports." Environment Systems and Decisions. Volume 40. Issue 1. 21 March 2020. doi:10.1007/s10669-020-09767-y

203

204

205

206

207

208

217 These experts were sought for their specialized knowledge and experience in seaport

agricultural sustainability, they all employed AHP as a means of quantifying expertpreferences for weighting the relative importance of the indicators used. AHP simplifies the process of quantifying subjective weight preferences based on multiple criteria by using pairwise comparisons. Participants are given two items at a time and asked which is more important with respect to the given category. Using pairwise comparisons not only helps discover and correct logical inconsistencies (Goepel 2013), it also allows for translating subjective opinions into numeric relations, helping make group decisions more rational, transparent, and understandable (Goepel 2013; Saaty 2008).

\section{Methodology}

\section{Expert Selection}

Researchers invited the same group of 64 experts who contributed to the evaluation of candidate indicators via the VAS survey to participate in this AHP weighting exercise.

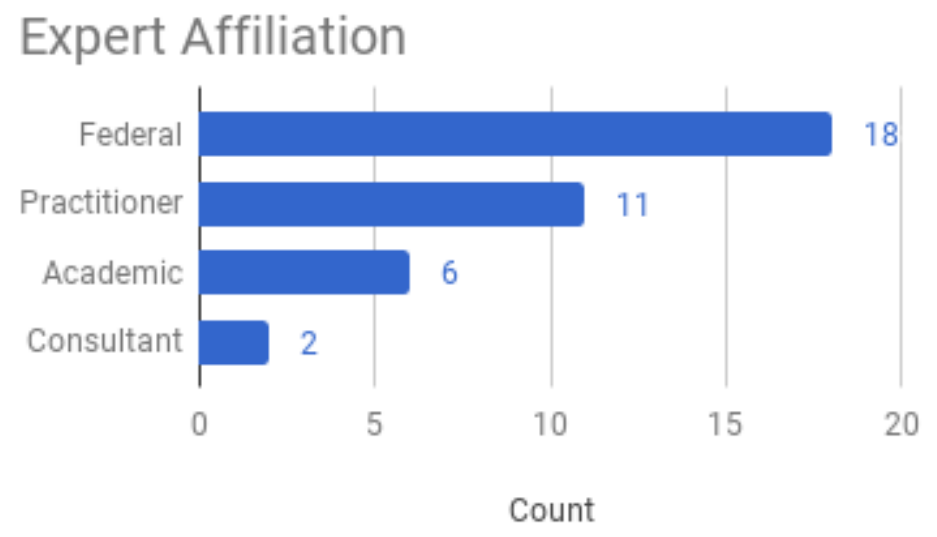

operations, planning, policy, data, and the vulnerability of the U.S. marine transportation system (MTS) to climate and extreme weather impacts. This group of expert-respondents was compiled via a knowledge resource nomination worksheet and peer snowball sampling. Out of this expert pool, 37 experts participated in this AHP exercise, representing the expert- 
McIntosh, R.D., Becker, A. (2020), “Applying MCDA to Weight Indicators of Seaport Vulnerability to Climate and Extreme Weather Impacts for U.S. North Atlantic Ports." Environment Systems and Decisions. Volume 40. Issue 1. 21 March 2020. doi:10.1007/s10669-020-09767-y

222 affiliation categories of: federal (e.g., US Coast Guard, NOAA, USACE, MARAD),

223 practitioners (e.g., port authorities), academics (e.g., professors, research analysts), and

224 consultants (Figure 4).

225 AHP

In the spring and summer of 2017 , researchers held 21 separate webinars with a total of 37 participating port-experts. During each webinar, researchers guided participants through a web-based AHP system (Goepel 2017). Experts were given a data dictionary with descriptions, units, data sources, and example values for each of the 12 indicators to be weighted. For the AHP exercise, as with the VAS survey, respondents were instructed to consider port vulnerability holistically, inclusive of the port's surrounding socioeconomic and environmental systems, and to focus on 22 the ports of the CENAD (Figure 1).

The AHP involved two levels; the first comprised weighting the three components of vulnerability (i.e., exposure, sensitivity, and adaptive capacity), and the second comprised weighting the six indicators of exposure and the six indicators of sensitivity (Figure 5). Because the VAS survey failed to develop expert-supported indicators of adaptive capacity

237 for seaport climate and extreme weather vulnerability, researchers were unable to include 238 indicators of adaptive capacity for weighting in this AHP. The lack of indicators of adaptive capacity, however, did not prevent the derivation of weight for adaptive capacity as a component of seaport vulnerability to climate and weather extremes. 
McIntosh, R.D., Becker, A. (2020), “Applying MCDA to Weight Indicators of Seaport Vulnerability to Climate and Extreme Weather Impacts for U.S. North Atlantic Ports.” Environment Systems and Decisions. Volume 40. Issue 1. 21 March 2020. doi:10.1007/s10669-020-09767-y

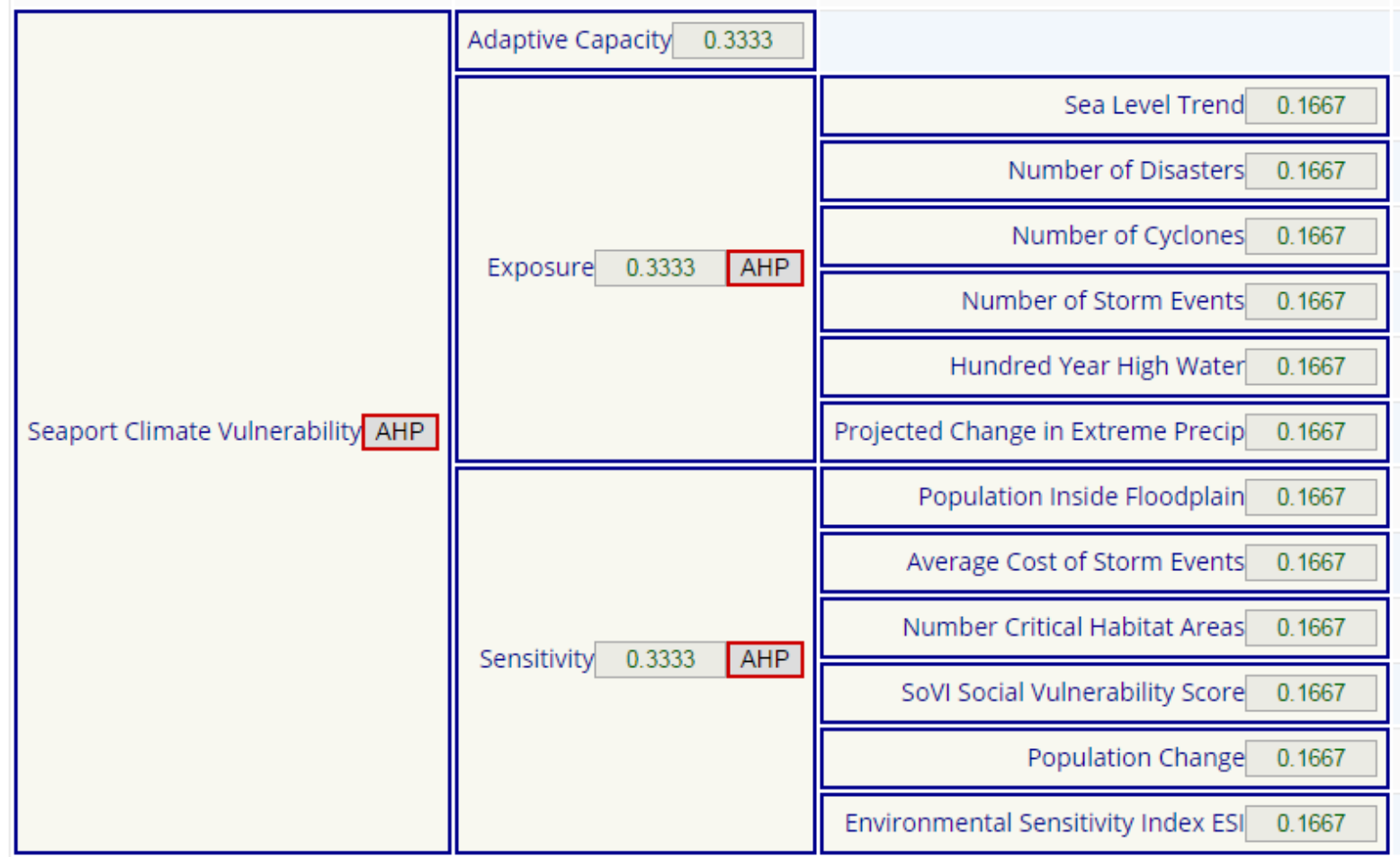

Figure 5 AHP hierarchy showing equal weighting prior to pairwise comparisons. Each column represents a level of the AHP, and each red rectangle indicates a node (for which a priority vector will be calculated).

For the first level of the AHP, respondents weighted the three components of seaport

245 vulnerability via pairwise comparisons. Respondents were given two components at a time

246 and asked, "With respect to seaport climate vulnerability, which criterion is more important,

247 and how much more on a scale 1 to 9," where ' 1 ' represents equal importance (Error!

\section{Reference source not found.).}


McIntosh, R.D., Becker, A. (2020), “Applying MCDA to Weight Indicators of Seaport Vulnerability to Climate and Extreme Weather Impacts for U.S. North Atlantic Ports." Environment Systems and Decisions. Volume 40. Issue 1. 21 March 2020. doi:10.1007/s10669-020-09767-y

\section{Pairwise Comparison Seaport Climate Vulnerability}

Please do the pairwise comparison of all criteria. When completed, click Check Consistency to get the priorities.

AHP Scale: 1- Equal Importance, 3- Moderate importance, 5- Strong importance, 7-Very strong importance, 9- Extreme importance (2,4,6,8 values inbetween).

With respect to Seaport Climate Vulnerability, which criterion is more important, and how much more on a scale 1 to 9 ?

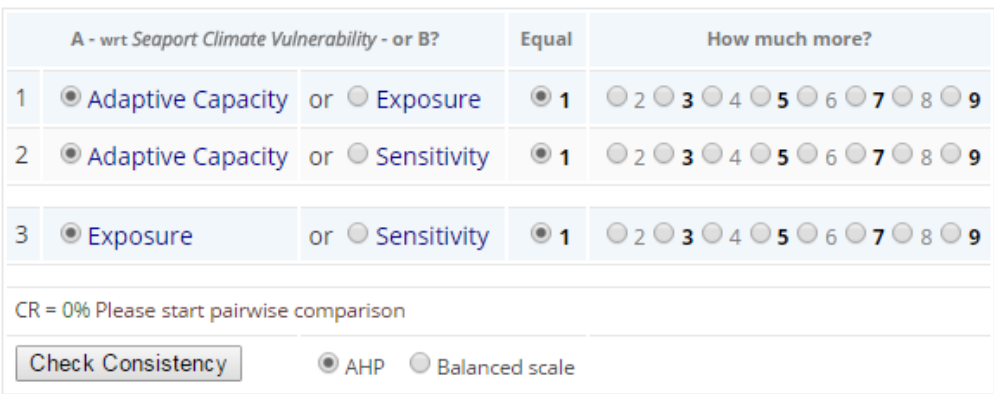

The second level of the AHP involved two nodes; weighting six indicators of exposure, and weighting six indicators of sensitivity. For the former, respondents were given two indicators at a time and asked, "With respect to seaport climate exposure, which criterion is more important, and how much more on a scale 1 to 9." For calculating the number of pairwise comparisons required, Equation 1 is used where $n$ is the number of components or indicators (Saaty 1977, 1990a; Orencio and Fujii 2013).

$$
(n)(n-1) / 2
$$

For the six indicators of exposure (Figure 5), respondents completed 15 pairwise comparisons, contrasting the relative importance of each indicator to every other indicator, one pair at a time. Similarly, the second node of this level of the AHP repeated this process with respect to sensitivity for the six indicators of seaport climate and extreme weather

264 sensitivity. For each respondent at each level of the AHP, the product of each paired comparison was recorded in a $n \times n$ square matrix, with $n$ equaling the number of indicators or components. 
McIntosh, R.D., Becker, A. (2020), “Applying MCDA to Weight Indicators of Seaport Vulnerability to Climate and Extreme Weather Impacts for U.S. North Atlantic Ports." Environment Systems and Decisions. Volume 40. Issue 1. 21 March 2020. doi:10.1007/s10669-020-09767-y

Let us denote the criteria that were ranked by experts as $\left[I_{1}, I_{2}, \ldots I_{n}\right]$, where $n$ is the number of components of vulnerability or the number of indicators compared. Based on experts' responses, a preference matrix was derived for each respondent, of the form:

Equation 2 Preference matrix for AHP

$$
A=\left[a_{i j}\right]\left[\begin{array}{cccc}
1 & a_{i j} & \cdots & a_{1 n} \\
1 / a_{i j} & 1 & \cdots & a_{2 n} \\
\vdots & \vdots & \ddots & \vdots \\
1 / a_{1 n} & 1 / a_{2 n} & \cdots & 1
\end{array}\right]
$$

Where $a_{i j}$ is the preference for indicator $I_{i}$ over $I_{j}$ when both were compared pairwise, for $i, j$ $=1,2, \ldots n$. If a respondent decided that indicator $i$ was equally important to another indicator $j$, a comparison of $a_{i j}=a_{j i}=1$ was recorded. If a respondent considered indicator $i$ extremely more important than indicator $j$, the preference-matrix score was based on $a_{i j}=9$ and its reciprocal given as $a_{j i}=1 / 9$, where $a_{i j}>0$.

After compiling a preference matrix for each expert for each node of the AHP, the dominant eigenvector of each matrix was then calculated using the power method (Larson 2016; Goepel 2013) with the number of iterations limited to 20, for an approximation error of $1 \times 10^{-7}$ (Goepel 2013). This normalized principal eigenvector, also called a priority vector ${ }^{12}$, gives the relative weights of the indicators and components of vulnerability that were compared.

The consistency of a respondent's answers was checked using the linear fit method (Equation 3) proposed by (Alonso and Lamata 2006) to calculate the consistency ratio, $C R$, for each respondent's preference matrix for each node of the AHP, where $\lambda_{\max }$ represents the principal eigenvalue obtained from the summation of products between each element of the priority vector and the sum of columns of the preference matrix, and $n$ represents the number of dimensions of the matrix.

\footnotetext{
${ }^{12}$ Because the vector is normalized, the sum of all elements in a priority vector is equal to one.
} 
McIntosh, R.D., Becker, A. (2020), “Applying MCDA to Weight Indicators of Seaport Vulnerability to Climate and Extreme Weather Impacts for U.S. North Atlantic Ports." Environment Systems and Decisions. Volume 40. Issue 1. 21 March 2020. doi:10.1007/s10669-020-09767-y

$$
C R=\frac{\lambda_{\max }-n}{2.7699 \cdot n-4.3513-n}
$$

If a respondent completed a node of pairwise comparisons that yielded a CR greater than $10 \%$, the software prompted the respondent to correct the inconsistencies by highlighting the three most inconsistent judgements and allowing adjustments.

Aggregation of individual judgements (AIJ) was based on the weighted geometric mean (WGM) of all participants' judgements (Aull-Hyde et al. 2006). The software calculated the geometric mean and standard deviation of all $K$ participants' individual

297 judgements $p w c_{k}$ to derive a consolidated preference matrix, $a_{i j}^{c o n s}$. The WGM-AIJ process consisted of summing individual judgements, $p w c$, over $K$ participants, squaring the sum, calculating the geometric mean of each $p w c$, and using the means to create a consolidated preference matrix (Equation 4).

$$
a_{i j}^{c o n s}=\left(\Pi_{k=1}^{K} a_{i j}\right)^{\frac{1}{K}}
$$

To measure the consensus for the aggregated group result, the AHP software used Shannon entropy and its partitioning in two independent components (alpha and beta diversity) to derive an AHP consensus indicator based on relative homogeneity $S$ (Goepel 2013). The consensus of the complete hierarchy was calculated as the weighted arithmetic mean of the consensus of all hierarchy nodes. This similarity measure, $S$, is zero when the priorities of all $p w c$ are completely distinct and $S=1$, when the priorities of all $p w c$ are identical (Goepel 2013).

\section{Aggregating Weighted Indicators}

After generating the indicator and component weights via AHP, the next step was to

312 create a composite index of seaport vulnerability based on the weightings. Due to the lack of 
McIntosh, R.D., Becker, A. (2020), “Applying MCDA to Weight Indicators of Seaport Vulnerability to Climate and Extreme Weather Impacts for U.S. North Atlantic Ports." Environment Systems and Decisions. Volume 40. Issue 1. 21 March 2020. doi:10.1007/s10669-020-09767-y

313 expert-supported indicators of adaptive capacity, the AHP-based composite index was limited

314 to the aggregation of two of the three components of vulnerability: exposure and sensitivity,

315 yielding a composite score that may be considered similar to vulnerability minus the 316 component of adaptive capacity. Researchers aggregated the indicators into a composite 317 indicator of vulnerability (minus adaptive capacity) using a weighted sum model (WSM)

318 (Equation 5). In Equation 5, $n$ represents the number of decision criteria (i.e., indicators or 319 components), $m$ represents the number of ports, $w_{j}$ represents the relative weight of indicator $320 I_{j}$, and $p_{i j}$ represents the performance of port $A_{i}$ when evaluated in terms of indicator $I_{j}$.

$$
A_{i}^{W S M-s c o r e}=\sum_{j=1}^{n} w_{j} p_{i j}, \text { for } i=1,2,3 \ldots, m .
$$
compiled data on all 12 indicators for the 22 ports of the CENAD. Missing values were imputed with the indicator's mean value. The input variables were then standardized using zscore standardization (Equation 6), generating variables with a mean of 0 and a standard deviation of 1 . This standardization allows for indicators with disparate units to be combined (Cutter et al. 2003).

$$
z=\frac{X-\mu}{\sigma}
$$

A composite indicator for exposure was then created by summing the products of each exposure indicator and its weight. Next, a composite indicator for sensitivity was created by summing the products of each sensitivity indicator and its weight. The two composite indicators of exposure and sensitivity were then each multiplied by their respective component weights and summed together. The resultant composite indicator represents the 
McIntosh, R.D., Becker, A. (2020), “Applying MCDA to Weight Indicators of Seaport Vulnerability to Climate and Extreme Weather Impacts for U.S. North Atlantic Ports." Environment Systems and Decisions. Volume 40. Issue 1. 21 March 2020. doi:10.1007/s10669-020-09767-y

336 combined exposure and sensitivity of the sample ports and was used to compile a composite

337 index of seaport vulnerability (minus adaptive capacity) for the CENAD sample of ports

338 based on publicly available data. The port-rankings generated by the composite index were

339 then compared to the experts' subjective raking of port vulnerability obtained from the VAS

340 survey.

$341 \quad$ Results

\section{AHP-Generated Weights}

343 The aggregation of judgements from the first level of the AHP, which weighted the

344 three components of seaport vulnerability to climate and extreme weather, resulted in

345 exposure ranked most important, with a ratio scale (weight) of .394 (Table 2). Adaptive

346 capacity was ranked a close second, with a weight of .390 , which is noteworthy since the

347 component of adaptive capacity lacks expert-supported indicators. Sensitivity was ranked

348 least important of the three components, with a weight of .216. For this node, the maximum

349 consistency ratio, $C R$, was $0.1 \%$ (highly consistent) and the group consensus, $S$, was $50.1 \%$

$350 \quad(\text { low })^{13}$.

Table 2 Results of AHP consolidated group preferences for the relative importance of the components of seaport climate and extreme weather vulnerability

The second level of the AHP consisted of two nodes, the first evaluated six indicators

356 for relative importance in terms of seaport exposure to climate and weather extremes, and the

\footnotetext{
13 (Goepel 2013) considers the following interpretation of AHP consensus; <50\% (very low), 50\%-65\% (low), $65 \%-75 \%$ (moderate), $75 \%-85 \%$ (high), $>85 \%$ (very high)
} 
McIntosh, R.D., Becker, A. (2020), “Applying MCDA to Weight Indicators of Seaport Vulnerability to Climate and Extreme Weather Impacts for U.S. North Atlantic Ports." Environment Systems and Decisions. Volume 40. Issue 1. 21 March 2020. doi:10.1007/s10669-020-09767-y

357 second node evaluated six indicators in terms of seaport sensitivity. The first node resulted in

358 the indicator "number of disasters," ranked most important for the component of exposure

359 with a weight of .200 , and resulted in weights for the remaining indicators of exposure as

360 shown in Table 3. For this node, the maximum consistency ratio, $C R$, was $0.3 \%$ (highly

361 consistent) and the group consensus, $S$, was $53.6 \%$ (low).

Table 3 Consolidated group preferences for the relative importance of indicators of seaport exposure to climate and weather extremes

\begin{tabular}{l|rr} 
Indicator of Exposure & Weight & Rank \\
\hline Number of Disasters & 0.200 & 1 \\
Number of Storm Events & 0.196 & 2 \\
Sea Level Trend & 0.180 & 3 \\
Hundred Year High Water & 0.163 & 4 \\
Number of Cyclones & 0.143 & 5 \\
Projected Change in Extreme & 0.118 & 6 \\
Precip & & \\
\end{tabular}

364

365 The second node of the second AHP level resulted in the indicator "population inside

366 floodplain," ranked most important for the component of sensitivity with a weight of .229,

367 and resulted in the remaining indicators of sensitivity weighted as shown in Table 4. For this

368 node, the maximum consistency ratio, $C R$, was $0.5 \%$ (highly consistent) and the group

369 consensus, $S$, was $61.1 \%$ (low).

Table 4 Consolidated group preferences for the relative importance of indicators of seaport sensitivity to climate and weather extremes

\begin{tabular}{l|rr} 
Indicator of Sensitivity & Weight & Rank \\
\hline Population Inside Floodplain & 0.229 & 1 \\
SoVI Social Vulnerability Score & 0.213 & 2 \\
Average Cost of Storm Events & 0.210 & 3 \\
Environmental Sensitivity Index ESI & 0.125 & 4 \\
Population Change & 0.119 & 5 \\
Number Critical Habitat Areas & 0.104 & 6
\end{tabular}


McIntosh, R.D., Becker, A. (2020), “Applying MCDA to Weight Indicators of Seaport Vulnerability to Climate and Extreme Weather Impacts for U.S. North Atlantic Ports." Environment Systems and Decisions. Volume 40. Issue 1. 21 March 2020. doi:10.1007/s10669-020-09767-y

372

373 These indicator weights were then used to generate a composite index of seaport vulnerability

374 (minus adaptive capacity) to climate and extreme weather impacts with a WSM (Equation 5).

\section{Composite Index of CENAD Ports}

To test the degree to which a ranking of ports by level of vulnerability to climate and extreme weather, created by a WSM using AHP-generated weights, would or would not resemble an a priori ranking generated ${ }^{14}$ subjectively by the same participating experts, researchers compiled a composite index for the CENAD sample of ports. Applying the AHPgenerated indicator weights to the z-score-standardized input variables for 22 CENAD ports, and aggregating them in a WSM yielded the following ranking (Table 5) where a larger number corresponds to a higher degree of vulnerability. In Table 5, a score of zero represents the mean, a negative number represents a vulnerability score below the mean, and a positive number represents a vulnerability score above the mean.

\begin{tabular}{l|r} 
Port & Vulnerability Score \\
\hline Virginia.VA.Port.of & 0.46 \\
Boston.MA & 0.24 \\
Philadelphia.PA & 0.11 \\
New.Haven.CT & 0.10 \\
Port.Jefferson.NY & 0.10 \\
Portland.ME & 0.10 \\
Hopewell.VA & 0.07 \\
Searsport.ME & 0.04 \\
Fall.River.MA & 0.02 \\
Camden-Gloucester.NJ & 0.02 \\
Baltimore.MD & 0.00 \\
Bridgeport.CT & -0.03
\end{tabular}

\footnotetext{
${ }^{14}$ As part of the VAS survey, port-experts were asked to rank the top ten most vulnerable ports out of the sample of 22 CENAD ports. The rank distribution (Table 6) was generated from a sum of weighted values, which were weighted as the inverse of the number of ports the respondent chose to rank.
} 
McIntosh, R.D., Becker, A. (2020), “Applying MCDA to Weight Indicators of Seaport Vulnerability to Climate and Extreme Weather Impacts for U.S. North Atlantic Ports." Environment Systems and Decisions. Volume 40. Issue 1. 21 March 2020. doi:10.1007/s10669-020-09767-y

\begin{tabular}{l|r} 
Port & Vulnerability Score \\
\hline Hempstead.NY & -0.04 \\
Paulsboro.NJ & -0.04 \\
Albany.NY & -0.05 \\
Wilmington.DE & -0.07 \\
Marcus.Hook.PA & -0.09 \\
Chester.PA & -0.10 \\
Penn.Manor.PA & -0.11 \\
Portsmouth.NH & -0.12 \\
New.York.NY.and.NJ & -0.12 \\
Providence.RI & -0.13
\end{tabular}

389 Interestingly, the most vulnerable port according to the model-generated port vulnerability rankings matches the most vulnerable port as subjectively ranked by experts in the VAS survey (Table 6). While the second most vulnerable port according to the subjective expertranking, the Port of New York and New Jersey, was second to least vulnerable according to the model rank, the model did capture three out of four of the most vulnerable ports consistent with the experts' rankings. weather.

\begin{tabular}{l|r} 
Port & Experts' Rank \\
\hline Virginia.VA.Port.of & 1 \\
New.York.NY.and.NJ & 2 \\
Boston.MA & 3 \\
New.Haven.CT & 4 \\
Baltimore.MD & 5 \\
Providence.RI & 6 \\
Portland.ME & 7 \\
Portsmouth.NH & 8 \\
Philadelphia.PA & 9 \\
Hempstead.NY & 10
\end{tabular}
variables into a single, measurable concept while still retaining the ability to explore the

400 disaggregated substructure behind the composite construct. As such, their users are able to 401 ask, "Why does a particular entity score high or low according to this index?" Figure 7 shows 
McIntosh, R.D., Becker, A. (2020), “Applying MCDA to Weight Indicators of Seaport Vulnerability to Climate and Extreme Weather Impacts for U.S. North Atlantic Ports." Environment Systems and Decisions. Volume 40. Issue 1. 21 March 2020. doi:10.1007/s10669-020-09767-y

402 the disaggregated substructure behind the composite 'vulnerability scores' of the three

403 highest scoring ports from the composite index, in which the relative performance of a port

404 can be explored in terms of the individual indicators. Similarly, Figure 8 shows the

405 disaggregated substructure for the three lowest scoring ports of the composite index.

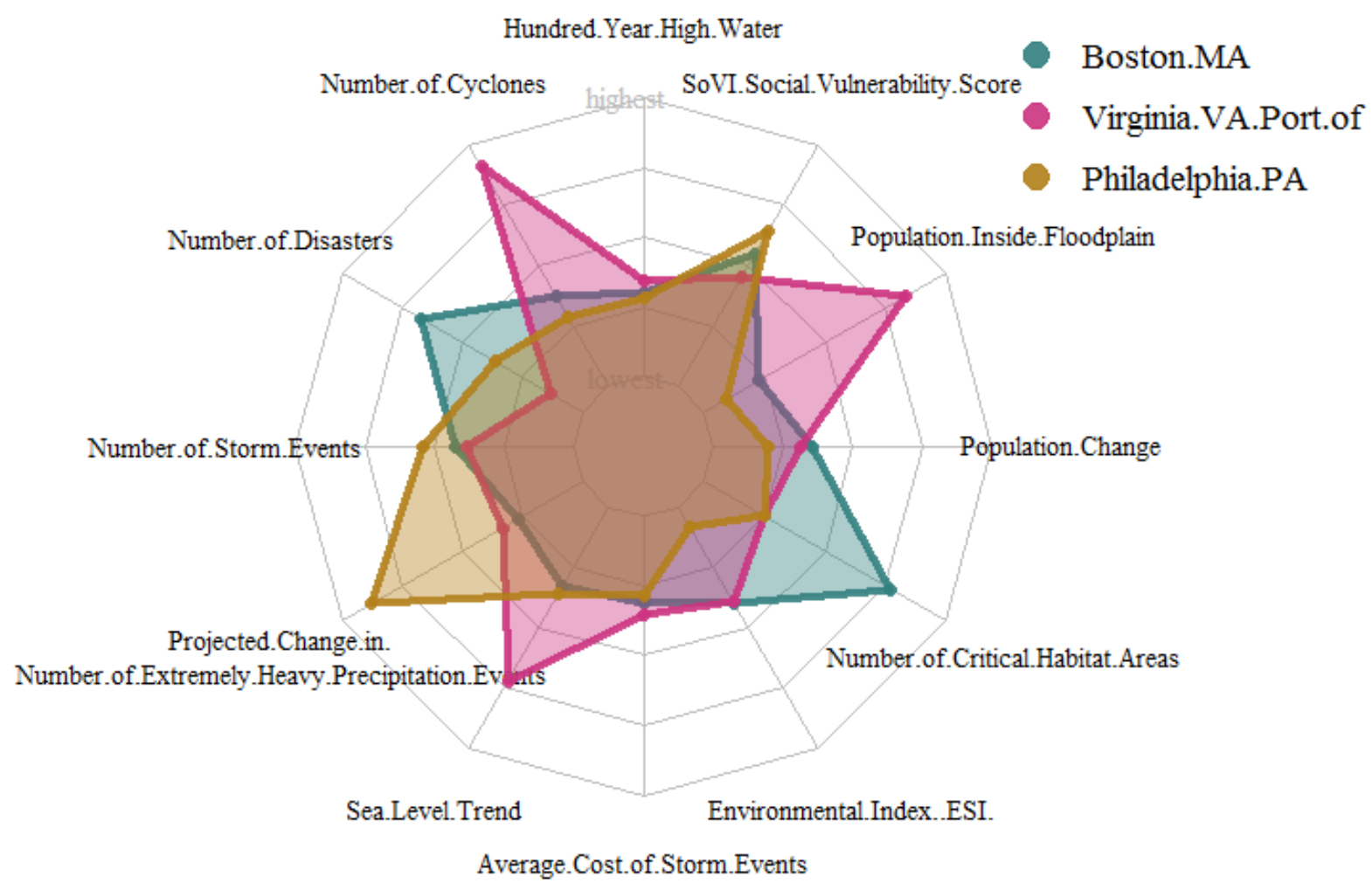

Average.Cost.of.Storm.Events

Figure 7 Disaggregated substructure of the composite-index vulnerability scores of the three highest scoring ports. Indicators of exposure are shown on the left half of the plot, and indicators of sensitivity are shown on the right half.

409 Comparing the three ports of Figure 7, reveals sharp differences in the underlying

410 performance of each port in terms of the individual indicators. Whereas the port of Virginia

411 scored high (i.e. relatively more vulnerable) in the 'number of cyclones' indicator and

412 relatively low with respect to the 'number of disasters,' the opposite is seen for the port of

413 Philadelphia. This type of differentiation can assist decision-makers in understanding the

414 mechanisms and drivers behind a 'composite score,' and tools that allow exploration of the

415 underlying substructure may add to the decision-relevance of indicator-based assessment

416 efforts and especially indicator-based composite indices. 
McIntosh, R.D., Becker, A. (2020), “Applying MCDA to Weight Indicators of Seaport Vulnerability to Climate and Extreme Weather Impacts for U.S. North Atlantic Ports." Environment Systems and Decisions. Volume 40. Issue 1. 21 March 2020. doi:10.1007/s10669-020-09767-y

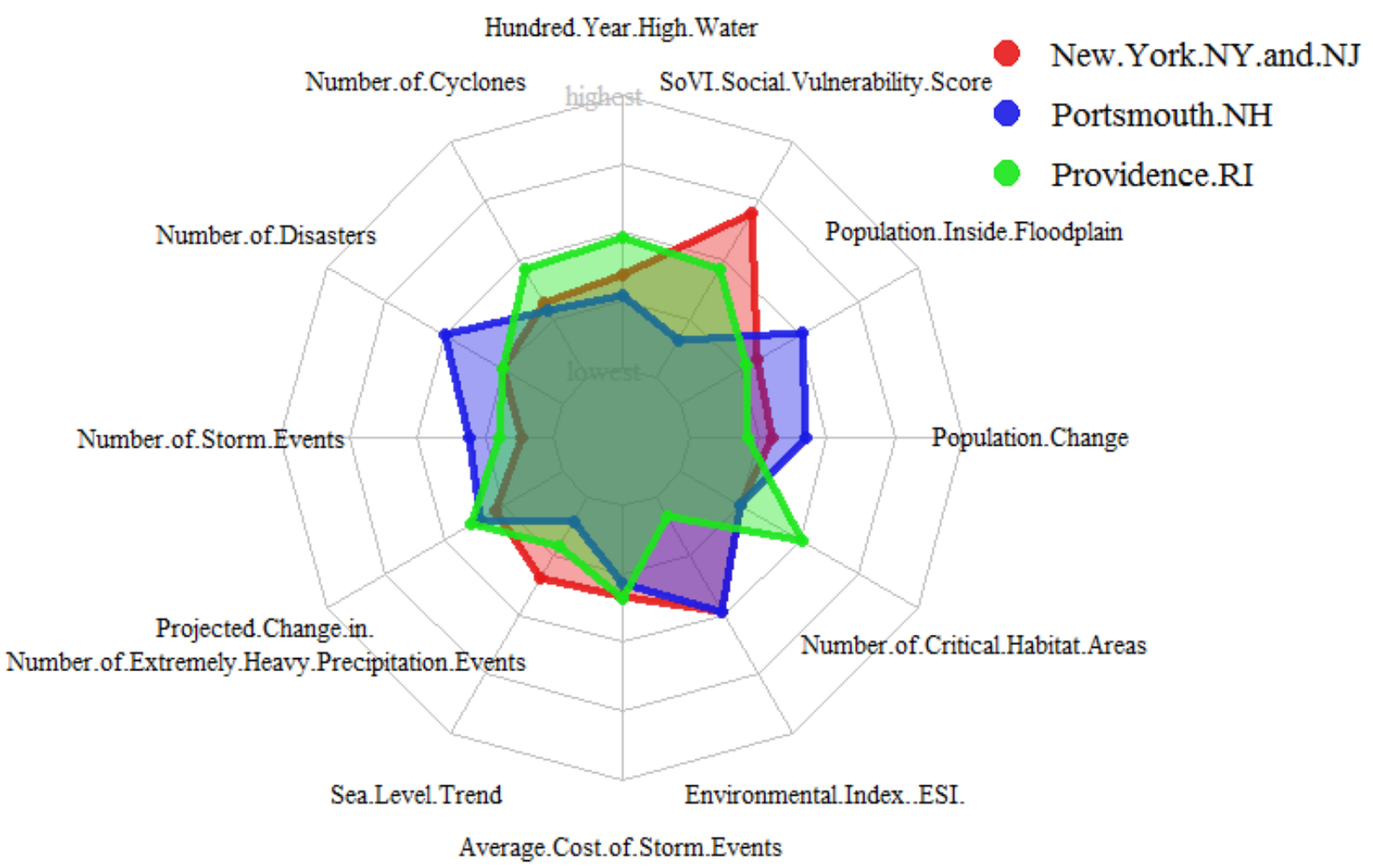

Figure 8 Disaggregated substructure of the composite-index vulnerability scores of the three lowest scoring ports. Indicators of exposure are shown on the left half of the plot, and indicators of sensitivity are shown on the right half.

Figure 8, showing the substructure of the three least vulnerable ports per the

composite index, yields insight into the discrepancy between the index rankings and the

subjective, expert-rankings. While the port of New York and New Jersey was considered

second most vulnerable according to expert-perception, the weighted-index scored it second

least vulnerable. Looking at Figure 8, we can see that while the port of New York and New

Jersey scored high (i.e., relatively more vulnerable) in the "SoVI social vulnerability score"

indicator, it scored near the bottom of the sample in nearly every other indicator. This may be

an artifact of the method of compiling the indicator data for the sample of ports. Most

indicators were measured at the county-level, and while the port of New York and New

Jersey spans multiple counties, for this experiment, the port of New York and New Jersey

was represented solely by New York County. Similarly, the port of Providence was

subjectively ranked sixth most vulnerable by port-experts yet scored least vulnerable of all in 
McIntosh, R.D., Becker, A. (2020), “Applying MCDA to Weight Indicators of Seaport Vulnerability to Climate and Extreme Weather Impacts for U.S. North Atlantic Ports." Environment Systems and Decisions. Volume 40. Issue 1. 21 March 2020. doi:10.1007/s10669-020-09767-y

433

434

435

436

437

438

440

441

442

443

444

445

446

447

448

449

450

451

452

453

454

455

456

sample for "number of critical habitat areas," "hundred year high water," and "number of cyclones," it scored near the bottom of the sample for "number of disasters," "number of storm events," and "environmental sensitivity index ESI," and did not score higher than average for any indicator.

\section{Discussion}

The method of generating indicator weights based on aggregated expert-preferences using AHP described in this paper has shown both promise and limitations. Port rankings generated by a composite index based on a WSM using the AHP-derived weights, was compared to an a priori subjective ranking generated by port experts. Though the model lacked indicators of adaptive capacity, it matched (Table 5) the experts' ranking for the most vulnerable port, and also matched three of the four ports ranked most vulnerable by the experts (Table 6).

Whereas previous work on assessing the climate vulnerability of seaports has tended to focus on the single port scale, either as case studies (Koppe et al. 2012; Cox et al. 2013; USDOT 2014; Messner et al. 2013; Chhetri et al. 2014) or as self-assessment tools (NOAA OCM 2015; Semppier et al. 2010; Morris and Sempier 2016), this work contributes a first attempt at constructing an indicator-based composite-index for the purpose of developing seaport CCVA at the multi-port scale.

To the observed problem (i.e., the current difficulty of comparing relative vulnerability across ports), this work contributes a prototype composite-index (and a method to replicate such an index for other sectors) that allows rudimentary quantitative comparisons of exposure and sensitivity levels across ports. This prototype index was able to capture relative outliers in the sample of ports (i.e., the main objective of composite-indices) and shows the promise of an indicator-based approach to address this problem. 
McIntosh, R.D., Becker, A. (2020), “Applying MCDA to Weight Indicators of Seaport Vulnerability to Climate and Extreme Weather Impacts for U.S. North Atlantic Ports." Environment Systems and Decisions. Volume 40. Issue 1. 21 March 2020. doi:10.1007/s10669-020-09767-y

To validate the results of the AHP, the AHP-generated weighting scheme was applied using a WSM to create a composite index for 22 CENAD ports that was compared to a subjective ranking of the ports by the same experts. This comparison revealed that while the model showed promise in fulfilling the main objective of composite indices (i.e., identification of relative outliers among a sample) by matching the top port and three out of the top four ports subjectively chosen as most vulnerable by the experts, there were considerable discrepancies between the model rank and the subjective, expert rank that point to some of the limitations of this method. Those limitations include the potential for low group consensus during the AHP, for which the remedy, Delphi-style iterations, contains its own limitation of increased time-cost. The validity of indicator-based methods is also limited by their sensitivity to small changes in the methods used to compile the individual indicators. Variations in spatial scale of available data can require subjective choices regarding the compilation of indicator data, e.g., how to compile indicator data for ports that span multiple counties. Additionally, the process of compiling indicators introduces other subjective decisions that affect model sensitivity, such as whether to use the max value or a measure of central tendency of a concept as an indicator. Because of both the sensitivity and subjectivity of these decisions, researchers recommend a stakeholder-based approach for the early stages of indicator development such as the expert-elicitation methods applied in (Mcleod et al. 2015; Teck et al. 2010). While this research has furthered the development of indicator-based assessment methods for the port sector by constructing and trialing a prototype compositeindex of seaport climate vulnerability, it should be noted that further work exploring the sensitivity of results to data compilation methods and developing a measure of adaptive capacity will be needed before such methods are robust enough for use in critical decision-

480 making. Finally, the main caveat of these methods is that they are always limited by the quality of the data that they incorporate. 
McIntosh, R.D., Becker, A. (2020), “Applying MCDA to Weight Indicators of Seaport Vulnerability to Climate and Extreme Weather Impacts for U.S. North Atlantic Ports." Environment Systems and Decisions. Volume 40. Issue 1. 21 March 2020. doi:10.1007/s10669-020-09767-y

\section{Adaptive Capacity Considered Highly Important}

Adaptive capacity is defined in the glossary of the IPCC Fifth Assessment Report (IPCC 2014) as “"The ability of systems, institutions, humans and other organisms to adjust to potential damage, to take advantage of opportunities, or to respond to consequences." As noted by Siders (Siders 2016), this definition bears some resemblance to generally accepted definitions of resilience, i.e., the ability to bounce back from an impact (McIntosh and Becker 2017; Linkov et al. 2014). As such, Siders recommends that adaptive capacity can be distinguished from resilience by ascribing the latter to maintaining stability by "bouncing back" to pre-shock conditions, and by taking adaptive capacity, to refer to the broader ability of a system to self-organize, learn, and embrace change to limit future harms (Klein et al. 2003; Siders 2016).

It may be significant that the AHP resulted in adaptive capacity ranked a close second to exposure in terms of importance with respect to seaport climate and extreme weather vulnerability (Table 2). This suggests that port-experts consider adaptive capacity to be more important than sensitivity and practically equal in importance to exposure with respect to seaport vulnerability. Though experts place a high degree of importance on adaptive capacity as a component of vulnerability, VAS survey results suggest that adaptive capacity may be the most difficult of the three components of seaport vulnerability to represent with quantitative data. While this discrepancy may point to a need to improve the data collection and sharing of metrics that can capture the concept of adaptive capacity for ports, it also suggests that the concept of adaptive capacity may be better captured by other, less quantitative assessment methods. This finding also suggests a disconnect between what experts perceive as an important component to understanding seaport vulnerability to meteorological and climatological threats and the types of data that are currently being reported and available to represent that component. 
McIntosh, R.D., Becker, A. (2020), “Applying MCDA to Weight Indicators of Seaport Vulnerability to Climate and Extreme Weather Impacts for U.S. North Atlantic Ports." Environment Systems and Decisions. Volume 40. Issue 1. 21 March 2020. doi:10.1007/s10669-020-09767-y

As noted by Brooks et al. (Brooks et al. 2005), adaptive capacity is a component of

508 vulnerability primarily associated with governance. Hence, next-step efforts to assess relative

509 levels of seaport adaptive capacity should start by examining ports' governance structures to

510 find measurable metrics to assess and compare the ports' ability to adjust, take advantage, or

511 respond to climate and weather impacts.

\section{$512 \quad$ Limitations}

A limitation of this AHP method can be the difficulty of achieving high levels of group consensus. For each of the three nodes of this AHP, the consensus indicator, $S$, was low $(50.1 \%, 53.6 \%, 61.1 \%)$, suggesting low relative homogeneity of expert preferences. Improvements in group consensus may be achieved by using iterative approaches such as the

517 Delphi ${ }^{15}$ method, in which participants are shown descriptive statistics of the group responses 518 and given the opportunity to revise their answers during subsequent iterations of the AHP, as was employed in (Orencio and Fujii 2013). A drawback of this iterative approach, however, is the additional time required to complete the process. For this study, researchers held 20 different webinars with a total of 34 experts to complete the AHP, lasting approximately 30 minutes to one hour each webinar. Experts may be more reluctant to participate the longer the process proposes to take. As the number of pairwise comparisons increases quickly due to 524 Equation 1, even a single-round AHP can become a considerable imposition on the time constraints of busy professional experts.

Though the aggregation of weighted indicators into a composite index was performed mainly as a means to validate the AHP-generated weights by comparing the port-rankings they produced via a WSM to a subjective port-ranking, the process also yielded insight into

\footnotetext{
15 The Delphi method is a structured communication technique designed to obtain opinion consensus of a group of experts by subjecting them to a series of questionnaires interspersed with feedback in the form of a statistical representation of the group response. The goal of employing the Delphi method is to reduce the range of responses and arrive at something closer to expert consensus.
} 
McIntosh, R.D., Becker, A. (2020), “Applying MCDA to Weight Indicators of Seaport Vulnerability to Climate and Extreme Weather Impacts for U.S. North Atlantic Ports." Environment Systems and Decisions. Volume 40. Issue 1. 21 March 2020. doi:10.1007/s10669-020-09767-y

the benefits and limitations of such methods. As a means to identify relative outliers among a sample, this method showed promise by successfully matching the most vulnerable port and three of the four most vulnerable ports as ranked subjectively by port-experts. While partially successful at identifying the relative outliers among our sample of ports, the composite index also ranked several ports (e.g., Providence, New York and New Jersey) near the bottom of the sample that experts had subjectively ranked near the top. Some of this discrepancy may be due to the sensitivity of indicator-based composite indices to differences in the interpretation of data used for the indicators. For example, an indicator for an entity that spans multiple counties, like the port of New York and New Jersey, could be represented by a measure of central tendency of the data for the collection of counties, by the data from the county with most extreme value, or by a single representative county. In this experiment, the single county of New York was taken to represent the port of New York and New Jersey for the purposes of compiling the indicator data, which may have resulted in lower than expected values for that port in some of the indicators. Additionally, indicator-based assessments are always limited by the quality of data available to incorporate into them.

Although the AHP weighted all three components of vulnerability, including adaptive capacity, and the composite index incorporated the weights for the components of exposure and sensitivity into the WSM, it should be noted that this composite index of seaport vulnerability to climate and extreme-weather did not include indicators of adaptive capacity. As such, the composite index is more accurately described as a weighted measure of seaport exposure and sensitivity to climate and weather extremes. This may have also contributed to some of the discrepancy between model results and the subjective ranking of ports which was based on a definition of vulnerability that included all three components (e.g., exposure, sensitivity, adaptive capacity). 
McIntosh, R.D., Becker, A. (2020), “Applying MCDA to Weight Indicators of Seaport Vulnerability to Climate and Extreme Weather Impacts for U.S. North Atlantic Ports." Environment Systems and Decisions. Volume 40. Issue 1. 21 March 2020. doi:10.1007/s10669-020-09767-y

Additionally, indicator-based methods are inherently limited by the availability of

554 data. For example, the lack of openly available data to serve as indicators of adaptive capacity resulted in the reduction of the composite index described here from an assessment of holistic vulnerability to one of exposure and sensitivity only.

\section{Conclusion}

To further the development of indicator-based assessment methods for the port sector, this study performed an AHP with 37 port-experts that developed weights for the three components of vulnerability (i.e., exposure, sensitivity, and adaptive capacity), and for a selection of 12 indicators of seaport exposure and sensitivity to climate and extreme weather impacts. The AHP resulted in adaptive capacity weighted higher than sensitivity and nearly equal to exposure in importance with respect to seaport climate and extreme weather vulnerability. This finding suggests a disconnect between what experts believe is an important component to understanding seaport vulnerability to meteorological and climatological threats and the types of data that are currently being reported and available to represent that component. While a composite index of seaport climate-vulnerability based on AHP generated weights showed promise in identifying relative outliers among a sample (i.e., hotspots of vulnerability), there were considerable discrepancies between the model rank and the subjective, expert rank that point to some of the limitations of this method. An opportunity for future research exists to develop an answer to what types of data, if any, experts would accept as more representative of the concept of seaport adaptive capacity than what data is currently available.

\section{Acknowledgements}

576 This work was funded in part through a United States Army Corps of Engineers Broad Area

577 Announcement Award entitled "Measuring vulnerability to inform resilience: Pilot study for

578 North Atlantic Medium and High--Use Maritime Freight Nodes,” US Army Corps of 
McIntosh, R.D., Becker, A. (2020), “Applying MCDA to Weight Indicators of Seaport Vulnerability to Climate and Extreme Weather Impacts for U.S. North Atlantic Ports." Environment Systems and Decisions. Volume 40. Issue 1. 21 March 2020. doi:10.1007/s10669-020-09767-y

579 Engineers Engineer Research and Development Center, Broad Area Announcement Grant:

580 W912HZ-16-C-0019.

\section{Works Cited}

583

584

585

586

587

588

589

590

591

592

593

594

595

596

597

598

599

600

601

602

603

604

605

606

607

608

609

610

611

612

613

614

615

616
Alonso JA, Lamata MT (2006) Consistency in the analytic hierarchy process: a new approach. International journal of uncertainty, fuzziness and knowledge-based systems $14(04): 445-459$

Asariotis R, Benamara H, Mohos-Naray V (2017) Port Industry Survey on Climate Change Impacts and Adaptation. UNCTAD Research Paper No. 18, vol UNCTAD/SER.RP/2017/18. United Nations Conference on Trade and Development,

Aull-Hyde R, Erdogan S, Duke JM (2006) An experiment on the consistency of aggregated comparison matrices in AHP. European Journal of Operational Research 171 (1):290295

Barnett J, Lambert S, Fry I (2008) The hazards of indicators: insights from the environmental vulnerability index. Annals of the Association of American Geographers 98 (1):102119

Beck MW, Heck Jr KL, Able KW, Childers DL, Eggleston DB, Gillanders BM, Halpern B, Hays CG, Hoshino K, Minello TJ (2001) The identification, conservation, and management of estuarine and marine nurseries for fish and invertebrates: a better understanding of the habitats that serve as nurseries for marine species and the factors that create site-specific variability in nursery quality will improve conservation and management of these areas. Bioscience 51 (8):633-641

Becker A, Acciaro M, Asariotis R, Cabrera E, Cretegny L, Crist P, Esteban M, Mather A, Messner S, Naruse S, Ng AKY, Rahmstorf S, Savonis M, Song DW, Stenek V, Velegrakis AF (2013) A note on climate change adaptation for seaports: a challenge for global ports, a challenge for global society. Climatic Change 120 (4):683-695. doi:DOI 10.1007/s10584-013-0843-z

Brooks N, Adger WN, Kelly PM (2005) The determinants of vulnerability and adaptive capacity at the national level and the implications for adaptation. Global environmental change 15 (2):151-163

Cegan JC, Filion AM, Keisler JM, Linkov I (2017) Trends and applications of multi-criteria decision analysis in environmental sciences: literature review. Environment Systems and Decisions 37 (2):123-133

Chhetri P, Corcoran J, Gekara V, Maddox C, McEvoy D (2014) Seaport resilience to climate change: mapping vulnerability to sea-level rise. Journal of Spatial Science:1-14. doi:10.1080/14498596.2014.943311

Cox RJ, Panayotou K, Cornwell RM (2013) Climate Risk Assessment for Avatiu Port and Connected Infrastructure. Water Research Lab, University of New South Wales, 
McIntosh, R.D., Becker, A. (2020), “Applying MCDA to Weight Indicators of Seaport Vulnerability to Climate and Extreme Weather Impacts for U.S. North Atlantic Ports." Environment Systems and Decisions. Volume 40. Issue 1. 21 March 2020. doi:10.1007/s10669-020-09767-y

617 Cutter SL, Boruff BJ, Shirley WL (2003) Social Vulnerability to Environmental Hazards*.

$618 \quad$ Social Science Quarterly 84 (2):242-261. doi:10.1111/1540-6237.8402002

619

620

621

622

623

624

625

626

627

628

629

630

631

632

633

634

635

636

637

638

639

640

641

642

643

644

645

646

647

648

649

650

651

652

Cutter SL, Burton CG, Emrich CT (2010) Disaster Resilience Indicators for Benchmarking Baseline Conditions. Journal of Homeland Security and Emergency Management 7 (1). doi:10.2202/1547-7355.1732

Davidson RA, Shah HC (1997) An urban earthquake disaster risk index. John A. Blume Earthquake Engineering Center Standford University,

Dedeke N (2013) Estimating the weights of a composite index using AHP: Case of the environmental performance index. British Journal of Arts \& Social Sciences 11:199221

Eriksen S, Kelly PM (2007) Developing credible vulnerability indicators for climate adaptation policy assessment. Mitigation and Adaptation Strategies for Global Change $12(4): 495-524$

Gallopin GC (1997) Indicators and their use: information for decision-making. In: Boldan B, Bilharz S (eds) Sustainability Indicators. A Report on the Project on Indicators of Sustainable Development, vol 58. SCOPE, Chichester, pp 13-27

Goepel KD Implementing the analytic hierarchy process as a standard method for multicriteria decision making in corporate enterprises-a new AHP excel template with multiple inputs. In: Proceedings of the international symposium on the analytic hierarchy process, 2013. pp 1-10

Goepel KD (2017) AHP Online System - BPMSG. https://bpmsg.com/academic/ahp.php.

Gómez-Limón JA, Riesgo L (2009) Alternative approaches to the construction of a composite indicator of agricultural sustainability: an application to irrigated agriculture in the Duero basin in Spain. Journal of Environmental Management 90 (11):3345-3362

Gudmundsson H (2003) The policy use of environmental indicators-learning from evaluation research. The Journal of Transdisciplinary Environmental Studies 2 (2):112

Hallegatte S, Ranger N, Mestre O, Dumas P, Corfee-Morlot J, Herweijer C, Wood RM (2011) Assessing climate change impacts, sea level rise and storm surge risk in port cities: a case study on Copenhagen. Climatic change 104 (1):113-137

Hinkel J (2011) "Indicators of vulnerability and adaptive capacity": Towards a clarification of the science-policy interface. Global Environmental Change-Human and Policy Dimensions 21 (1):198-208. doi:DOI 10.1016/j.gloenvcha.2010.08.002

Hovanov NV, Kolari JW, Sokolov MV (2008) Deriving weights from general pairwise comparison matrices. Mathematical Social Sciences 55 (2):205-220 
McIntosh, R.D., Becker, A. (2020), “Applying MCDA to Weight Indicators of Seaport Vulnerability to Climate and Extreme Weather Impacts for U.S. North Atlantic Ports." Environment Systems and Decisions. Volume 40. Issue 1. 21 March 2020. doi:10.1007/s10669-020-09767-y

653

654

655

656

657

658

659

660

661

662

663

664

665

666

667

668

669

670

671

672

673

674

675

676

677

678

679

680

681

682

683

684

685

686

687

688

IPCC (2001) Climate change 2001: impacts, adaptation, and vulnerability: contribution of Working Group II to the third assessment report of the Intergovernmental Panel on Climate Change. Intergovernmental Panel on Climate Change,

IPCC (2014) WGII AR5 Glossary. Fifth Assessment Report of the Intergovernmental Panel on Climate Change. IPCC, Geneva, Switzerland

Ishizaka A, Labib A (2011) Review of the main developments in the analytic hierarchy process. Expert systems with applications 38 (11):14336-14345

Kainulainen T, Leskinen P, Korhonen P, Haara A, Hujala T (2009) A statistical approach to assessing interval scale preferences in discrete choice problems. Journal of the Operational Research Society 60 (2):252-258

Klein RJ (2009) Identifying countries that are particularly vulnerable to the adverse effects of climate change: an academic or political challenge. Carbon \& Climate L Rev:284

Klein RJ, Nicholls RJ, Thomalla F (2003) Resilience to natural hazards: How useful is this concept? Global Environmental Change Part B: Environmental Hazards 5 (1-2):35-45

Koppe B, Schmidt M, Strotmann T (2012) IAPH-Report on Seaports and Climate Change and Implementation Case Study for the Port of Hamburg.

Kurth MH, Larkin S, Keisler JM, Linkov I (2017) Trends and applications of multi-criteria decision analysis: use in government agencies. Environment Systems and Decisions 37 (2):134-143

Larson R (2016) Elementary linear algebra. Nelson Education,

Linkov I, Bridges T, Creutzig F, Decker J, Fox-Lent C, Kröger W, Lambert JH, Levermann A, Montreuil B, Nathwani J, Nyer R, Renn O, Scharte B, Scheffler A, Schreurs M, Thiel-Clemen T (2014) Changing the resilience paradigm. Nature Climate Change 4 (6):407-409. doi:10.1038/nclimate2227

Linkov I, Moberg E (2011) Multi-criteria decision analysis: environmental applications and case studies. CRC Press,

Linkov I, Ramadan AB (2004) Comparative risk assessment and environmental decision making, vol 38. Springer Science \& Business Media,

McIntosh RD, Becker A (2017) Seaport Climate Vulnerability Assessment at the Multi-port Scale: A Review of Approaches. In: Linkov I, Palma-Oliveira JM (eds) Resilience and Risk: Methods and Application in Environment, Cyber and Social Domains. NATO Science for Peace and Security Series C: Environmental Security. Springer Netherlands, Dordrecht, pp 205-224. doi:10.1007/978-94-024-1123-2_7

McIntosh RD, Becker A (2019) Expert evaluation of open-data indicators of seaport vulnerability to climate and extreme weather impacts for US North Atlantic ports. Ocean \& Coastal Management 180:104911 
McIntosh, R.D., Becker, A. (2020), “Applying MCDA to Weight Indicators of Seaport Vulnerability to Climate and Extreme Weather Impacts for U.S. North Atlantic Ports." Environment Systems and Decisions. Volume 40. Issue 1. 21 March 2020. doi:10.1007/s10669-020-09767-y

689

690

691

692

693

694

695

696

697

698

699

700

701

702

703

704

705

706

707

708

709

710

711

712

713

714

715

716

717

718

719

720

721

722

723

724

725

726

727

McIntosh RD, Mclean E, Becker A (2019) Measuring climate and extreme weather vulnerability to inform resilience, report 1: A pilot study for North Atlantic mediumand high-use maritime freight. U.S. Army Engineer Research and Development Center, Coastal and Hydraulics Laboratory, Vicksburg, MS. doi:10.21079/11681/35196

McLaughlin BJ, Murrell SD, DesRoches S Case study: Assessment of the vulnerability of Port Authority of NY \& NJ facilities to the impacts of climate change. In: First Congress of Transportation and Development Institute (TDI), 2011.

Mcleod E, Szuster B, Tompkins EL, Marshall N, Downing T, Wongbusarakum S, Patwardhan A, Hamza M, Anderson C, Bharwani S (2015) Using Expert Knowledge to Develop a Vulnerability and Adaptation Framework and Methodology for Application in Tropical Island Communities. Coastal Management 43 (4):365-382

Messner S, Moran L, Reub G, Campbell J (2013) Climate change and sea level rise impacts at ports and a consistent methodology to evaluate vulnerability and risk. ENVIRON International Corp. doi:10.2495/CP130131

Morris LL, Sempier T (2016) Ports Resilience Index: A Port Management Self-Assessment. U.S. Department of Commerce, Gulf of Mexico Alliance,

NOAA OCM (2015) Port Tomorrow: Port Resilience Planning Tool [Prototype]. NOAA Office for Coastal Management. http://www.coast.noaa.gov/port/. Accessed 3 April 20152015

Orencio PM, Fujii M (2013) A localized disaster-resilience index to assess coastal communities based on an analytic hierarchy process (AHP). International Journal of Disaster Risk Reduction 3:62-75

Peduzzi P, Dao H, Herold C, Mouton F (2009) Assessing global exposure and vulnerability towards natural hazards: the Disaster Risk Index. Nat Hazards Earth Syst Sci 9 (4):1149-1159. doi:10.5194/nhess-9-1149-2009

Pticina I, Yatskiv I (2015) Weighting the urban public transport system quality index (UPTQI) using the analytical hierarchy process. International Journal of Society Systems Science 7 (2):107-126

Ramanathan R, Ganesh L (1994) Group preference aggregation methods employed in AHP: An evaluation and an intrinsic process for deriving members' weightages. European Journal of Operational Research 79 (2):249-265

Rosati JD (2015) PhD, PE, D.CE, Coastal \& Hydraulics Laboratory, Engineer Research \& Development Center, U.S. Army Corps of Engineers. USACE, Personal Communication

Saaty TL (1977) A scaling method for priorities in hierarchical structures. Journal of mathematical psychology 15 (3):234-281

Saaty TL (1990a) An exposition of the AHP in reply to the paper "remarks on the analytic hierarchy process". Management science 36 (3):259-268 
McIntosh, R.D., Becker, A. (2020), “Applying MCDA to Weight Indicators of Seaport Vulnerability to Climate and Extreme Weather Impacts for U.S. North Atlantic Ports." Environment Systems and Decisions. Volume 40. Issue 1. 21 March 2020. doi:10.1007/s10669-020-09767-y

Saaty TL (1990b) How to make a decision: the analytic hierarchy process. European journal of operational research 48 (1):9-26

Saaty TL (2006) Rank from comparisons and from ratings in the analytic hierarchy/network processes. European Journal of Operational Research 168 (2):557-570

Saaty TL (2008) Decision making with the analytic hierarchy process. International journal of services sciences $1(1): 83-98$

Sagar AD, Najam A (1998) The human development index: a critical review1. Ecological economics 25 (3):249-264

Semppier TT, Swann DL, Emmer R, Sempier SH, Schneider M (2010) Coastal Community Resilience Index: A Community Self-Assessment. Mississippi-Alabama Sea Grant Consortium,

Siders A (2016) Incoherent Resilience -- Towards a Common Language for Climate Change Adaptation, Disaster Risk Reduction, and Sustainable Development [Pre-Print Version].

Teck SJ, Halpern BS, Kappel CV, Micheli F, Selkoe KA, Crain CM, Martone R, Shearer C, Arvai J, Fischhoff B (2010) Using expert judgment to estimate marine ecosystem vulnerability in the California Current. Ecological Applications 20 (5):1402-1416

USACE (2014) USACE Civil Works Division Boundaries. U.S. Army Corps of Engineers, http://geoplatform.usace.army.mil/home/item.html?id=c3695249909c45a2b2e2c3993 $\underline{\text { aff3edb }}$

USDOT (2014) Impacts of Climate Change and Variability on Transportation Systems and Infrastructure The Gulf Coast Study, Phase 2 Screening for Vulnerability Final Report, Task 3.1. US Department of Transportation, Washington, DC

White DD, Wutich A, Larson KL, Gober P, Lant T, Senneville C (2010) Credibility, salience, and legitimacy of boundary objects: water managers' assessment of a simulation model in an immersive decision theater. Science and Public Policy 37 (3):219-232 